\title{
Diversidade genética em caprino Marota e manejo genético para rebanhos de conservação
}

Oliveira Moura, J. ${ }^{@}$; Guimarães Campelo, J.E. ${ }^{\text {; }}$ Bajay, M.M. ${ }^{2}$; Lindenberg Rocha Sarmento, J. ${ }^{\text {; }}$ Barros Britto, F. ${ }^{3}$; Leal, T.M. ${ }^{\text {; }}$; Silva Costa, M. '; Helcias Cavalcante, D. '; Figueiredo Carvalho, M.D. ' e Mello Araújo, A. ${ }^{3}$

'Universidade Federal do Piauí. Brasil.

2Universidade Estadual de São Paulo. Brasil.

${ }^{3}$ Embrapa Meio Norte. Brasil.

PALAVRAS CHAVE ADICIONAIS

Microarranjos.

Recursos genéticos.

Risco de extinç̃o.

SNP.

\section{RESUMO}

Objetivou-se avaliar a diversidade genética em rebanhos de caprinos Marota e verificar o impacto do uso de marcadores moleculares no manejo genético em rebanho de conservação. Utilizando-se Chip SNP caprino 50K genotipou-se 76 animais do rebanho de conservação institucional e 10 animais de um rebanho particular. Avaliouse a dispersão dos animais por Análise de Componentes Principais (PCA) e em dendograma. Simulou-se acasalamentos entre animais que apresentaram maior distância no dendograma e menor coeficiente de consanguinidade (FIS) (Manejo I) para verificar a eficiência desse manejo, em relação à ocorrência de acasalamentos ao acaso (Manejo II). Valores altos de heterozigosidade observada (Ho) e esperada $(\mathrm{He})$ nos animais adultos $(\mathrm{Ho}=0,372 \pm 0,005$ e He$=0,405 \pm 0,007)$ e nas crias $(\mathrm{Ho}=0,359 \pm 0,012$ e He$=0,374 \pm 0,028)$ e média do FIS igual a 6,4\% indicam baixo risco de perda de genes no rebanho institucional. O rebanho particular também apresentou variabilidade genética $(\mathrm{Ho}=0,374$ e He=0,498), porém com maior risco em relação à endogamia ( $F \mid S=22,7 \%$ ). A PCA indicou semelhança genética entre os rebanhos. A simulação de 10 pares de acasalamentos de cada reprodutor indicou que a média do coeficiente de consanguinidade dos casais formados de acordo com o Manejo I, foi estatisticamente inferior à média dos pares acasalantes formados de acordo com - Manejo II. Concluiuse que existe variabilidade genética nos rebanhos analisados, porém com indício de consanguinidade; e que em rebanhos pequenos nos quais a reposição é feita com animais do próprio rebanho, a definição de acasalamentos com base em critérios genéticos, é opção para controle de consanguinidade.

\section{Genetic diversity in Matora goats and genetic management of conservation herds}

\section{SUMMARY}

\section{ADDITIONAL KEYWORDS}

Microarray.

Genetic resources.

Risk of extinction.

SNP.

\section{INFORMATION}

\section{Cronología del artículo.}

Recibido/Received: 19.11.2017

Aceptado/Accepted: 26.12.2017

On-line: 15.01 .2019

Correspondencia a los autores/Contact e-mail:

jeaneprofessora@hotmail.com
This study was aimed at assessing the genetic diversity in herds of Marota goats and examine the impact of molecular markers in the genetic management of conservation herds. Seventy-six animals of one conservation heard and ten animals of a private herd were genotyped with the lllumina 50K goat SNP Chip. The dispersion of animal was evaluated with a principal component analysis (PCA) and a dendogram. Matings were simulated between animals with the largest distance in the dendogram and lowest coefficient of inbreeding (FIS) (Management I) and compared to random mating (Management II). High values of observed ( $\mathrm{Ho}$ ) and expected $(\mathrm{He})$ heterozygosity were obtained for adult animals $(\mathrm{Ho}=0.372$ and $\mathrm{He}=0.405)$ and offspring $(\mathrm{Ho}=0.359$ and $\mathrm{He}=0.374$ ). The mean $\mathrm{FIS}$ was $6.4 \%$, indicating a low risk of gene loss in the conservation herd. Genetic variability was also observed in the private herd $(\mathrm{Ho}=0.374$ and $\mathrm{He}=0.498)$, but the risk of endogamy was higher. The PCA revealed that the two herds were genetically similar. The simulation of 10 mating pairs of each breeder indicated that the mean coefficient of inbreeding of the formed pairs in Management I was statistically lower than that of the Management II. Thus, there is genetic variability in the herds examined, but with with signs of consanguinity. Also, in small herds in which replacement is carried out with animals within the herd, matings based on genetic criteria is an option to control inbreeding.

\section{INTRODUÇÃO}

Os caprinos trazidos para o Brasil no período da colonização portuguesa foram submetidos à seleção natural e originaram raças com características peculiares de adaptação, sendo conhecidos como "raças ou grupos genéticos locais" (Mariante et al., 2011). Durante o processo de adaptação às condições adversas do semiárido do Nordeste do país perderam características de desempenho produtivo, o que levou a terem importância apenas regional (Egito et al., 2002), 
ou como provável fonte de genes de adaptação a ambiente quente.

Um exemplo típico é o caprino do grupo genético Marota, que, segundo Araújo et al. (2009) representa um material genético importante para manutenção da biodiversidade dos animais domésticos. Apesar de sua importância, esses animais encontram-se em risco de extinção e vem sendo mantido em programa institucional de conservação in situ no semiárido do Piauí, estado localizado no Nordeste do Brasil.

Geralmente as raças em risco de extinção são mantidas em pequenas populações, o que pode agravar os efeitos da consaguinidade e favorecer a perda de genótipos relacionados com adaptação. Segundo Barros et al. (2011), a raça caprina Marota, constitue um patrimônio biológico e cultural único, relacionado à rusticidade adquirida em resposta a intempéries ambientais, merecendo atenção especial para a garantia da manutenção de sua variabilidade e da sua identidade como grupo genético local.

No Brasil, há limitações financeiras que comprometem a conservação de raças, e, por ser pequeno o número de animais em rebanhos de conservação, estes devem, verdadeiramente, representar a variabilidade genética do grupo. Assim, a caracterização genética de animais em rebanho de conservação ganha ainda mais importância, principalmente, se for utilizada para auxiliar o manejo genético do rebanho, pois poderá contribuir com a manutenção ou até mesmo com a ampliação da variabilidade genética de forma eficiente.

Entre as opções técnicas disponíveis para ampliação de variabilidade genética em rebanho de conservação, Silva Filho (2012) chama atenção para a introdução de progenitores de outros rebanhos, porém, preferencialmente que não tenham relação de parentesco direta com o rebanho em questão, sem indícios de erosão genética e que a consanguinidade esteja controlada.

Outra opção seria interferir no manejo dos animais, selecionando progenitores tanto com base em critérios de desempenho em características influenciáveis pelo ambiente, como também incluir indicador de variabilidade genética indiferente a variações ambientais, como o marcador molecular do tipo SNP (Single Nucleotide Polymorphism), que é a forma de variação mais frequente do DNA (Caetano, 2009; Curi et al. 2013; Resende et al., 2008). Em relação a outros marcadores, têm como vantagens: a facilidade de genotipagem (Resende et al., 2008) e a possibilidade de detecção de elevada quantidade de polimorfismos.

Logo, a constatação de aumento da consanguinidade ou de déficit de heterozigosidade, com base nesses marcadores, deve ser vista como um sinal de alerta de que é necessário recorrer a medidas práticas que inibam a perda da variabilidade, para impedir a perda de diversidade genética.

Diante disso, objetivou-se quantificar a variabilidade genética e verificar o impacto do uso de Chip SNP caprino 50K no manejo genético de um rebanho de conservação do caprino Marota.

\section{MATERIAL E MÉTODOS}

Os procedimentos metodológicos realizados foram aprovados pelo Comitê de Ética e Pesquisa com Animais da Universidade Federal do Piauí, onde o projeto encontra-se cadastrado com o número 058/14.

Avaliou-se o rebanho de conservação in situ institucional mantido pela Embrapa Meio Norte no estado do Piauí e, para servir como parâmetro de comparação relativo à diversidade genética, bem como um rebanho particular, que utiliza o rebanho institucional como uma de suas opções para reposição de animais.

O rebanho do Núcleo de Conservação genética institucional está localizado no município de Castelo

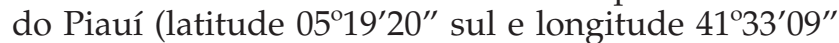
oeste), sendo composto por 111 animais, dos quais 76 foram utilizados nesse estudo. Amostrou-se 18 machos e 45 fêmeas em idade reprodutiva, independentemente da relação de parentesco, além de crias (13 crias) contemporâneas no primeiro semestre de 2014.

O rebanho privado avaliado, localiza-se no município de Elesbão Veloso-PI (latitude $06^{\circ} 12^{\prime} 07^{\prime \prime}$ sul e longitude $42^{\circ} 08^{\prime} 25^{\prime \prime}$ oeste) e na data de coleta dos dados se encontrava formado por 32 animais, dos quais 1 macho e 9 fêmeas foram amostrados de forma aleatória para participar do estudo.

A extração de DNA foi realizada a partir de sangue coletado diretamente na veia jugular, utilizando-se tubo Vacutainer ${ }^{\circledR}$ contendo fluoreto de sódio, que é um inibidor glicolítico, e EDTA, que preserva a morfologia celular. O procedimento de isolamento de DNA foi realizado com uso de Kit de extração AxyPrep Blood Genomic DNA Miniprep, comercializado pela Axygen Biosciences.

Em seguida, foi realizada a genotipagem das 86 amostras utilizando-se o Chip de SNPs caprino 50K da Illumina. O protocolo de genotipagem foi realizado segundo as recomendações de seu fabricante (Illumina, 2013), que estão numeradas a seguir: 1) Amplificação isotérmica do DNA; 2) Incubação das amostras (over night); 3) Fragmentação das amostras; 4) Precipitação e ressuspensão do DNA; 5) Preparação do BeadChip; 6) Hibridização (over night); 7) Extensão enzimática de uma única base; 8) Visualização das imagens na plataforma iScan e 9) Resultados gerados e armazenados em planilhas.

Foram excluídos das análises marcadores SNPs pertencentes aos cromossomos sexuais, com Call Rate menor que 95\%, com Alelo de Menor Frequência (MAF) inferior a $5 \%$ e que se mostraram em desequilíbrio de Hardy Weinberg, determinado pelo teste exato de Fisher com 1000 permutações e considerando $\mathrm{P}<5 \%$.

Para a exclusão de determinada amostra os critérios foram: apresentar Call Rate $<90 \%$, ou seja, apresentar menos de $90 \%$ de genótipos determinados pelo painel de genotipagem; apresentar heterozigosidade acima de três desvios padrões em relação à média; genótipos idênticos ( $>99,5 \%)$ e erro de identificação do sexo, no caso de indivíduos identificados como machos apresentarem genótipos heterozigotos para marcadores no cromossomo X. 
Para avaliação da qualidade dos dados e para calcular o coeficiente de consanguinidade individual dos animais utilizou-se o programa Plink versão 1.9 (Purcell et al., 2007).

A heterozigosidade observada $\left(\mathrm{H}_{\mathrm{o}}\right)$, heterozigosidade esperada $\left(\mathrm{H}_{\mathrm{e}}\right)$ e o coeficiente de endogamia $\left(\mathrm{F}_{\mathrm{IS}}\right)$, foram calculados utilizando-se o pacote hierfstat (versão 0.04-22, 2005) da plataforma $R$ (The R Project for Statistical Computing, versão 3.2.3) (Goudet, 2005).

$\mathrm{Na}$ perspectiva de recomendar a permuta de animais entre os rebanhos, a diversidade genética dos dois rebanhos foi avaliada com a utilização da Análise de Componentes Principais (PCA), utilizando-se a Matriz de Distância Euclidiana obtida através do pacote Adegenet (versão 2.0.1) da Plataforma R (The R Project for Statistical Computing, versão 3.2.3) (Jombart \& Ahmed, 2011).

A matriz de Distância de Nei foi obtida e usada na construção de dendrograma do rebanho institucional, com os animais estratificados em macho e fêmea, utilizando-se o Pacote Poppr (versão 2.1.0) do R (Kamvar et al., 2014.) e o método de agrupamento UPGMA (Sokal \& Michener, 1958). A consistência dos nós foi estimada utilizando-se o critério de Bootstraps com 1.000 reamostragens.

Levando-se em consideração que a reposição feita com animais do próprio rebanho é um procedimento que implica em aumento de consanguinidade e pode levar a perda de variabilidade genética, utilizou-se os resultados das análises genômicas dos animais do rebanho de conservação institucional, o coeficiente de consanguinidade individual e a distribuição de machos e fêmeas em dendograma, para dar suporte à discussão sobre descarte, reposição e a forma de acasalamentos em rebanhos de conservação com pequeno tamanho efetivo.

Para isso, considerou-se a realização de uma Estação de monta com cinco reprodutores, simulando o que tem sido feito no rebanho de conservação institucional, e duas situações de manejo:

\section{Manejo I:}

Para valorizar a capacidade de adaptação dos animais ao ambiente de criação, considerou-se que dois reprodutores ( $40 \%$ dos reprodutores utilizados) fossem selecionados com base no desempenho em características influenciadas pelo ambiente (produção, reprodução ou sanidade) para serem acasalados com qualquer fêmea do rebanho.

Para contemplar a variabilidade genética e contribuir para o controle da endogamia, que é o maior problema em rebanhos de conservação, considerou-se que os outros três reprodutores $(60 \%$ dos reprodutores utilizados no manejo) fossem escolhidos entre os de menor coeficiente de consanguinidade e que ocupassem posições em ramos distantes no dendrograma, obtido com base em dados moleculares, que são indiferentes a alterações no ambiente.

Na seleção de fêmeas, considerou-se critérios semelhantes aos empregados na escolha dos machos, mas com menor pressão de seleção, aceitando-se mais de uma fêmea por ramo do dendrograma, para adequar a relação macho/fêmea do rebanho.

\section{Manejo II:}

Considerou-se a escolha de cinco reprodutores para serem acasalados aleatoriamente, através de sorteio, com as matrizes disponíveis, manejados como reprodutores múltiplos, como ocorre no rebanho institucional de conservação do caprino Marota.

Para a discussão das vantagens do Manejo I em relação ao Manejo II, escolheram-se três reprodutores e trinta matrizes do rebanho com base na maior distância no dendrograma, dentre os de menor coeficiente de consanguinidade individual (Manejo I), e três reprodutores e trinta matrizes por sorteio (Manejo II). Simulou-se o acasalamento de cada reprodutor com 10 matrizes, considerando-se entre eles a maior distância gráfica no dendrograma e o menor coeficiente de consanguinidade (Manejo I) e entre os animais escolhidos por sorteio (Manejo II).

Em seguida, calculou-se a média dos coeficientes de consanguinidade dos casais formados em cada Manejo e realizou-se a análise de variância, considerando os dois manejos como tratamentos com 30 repetições (cada um dos três reprodutores com 10 matrizes). As duas médias do coeficiente de consanguinidade foram comparadas pelo teste $\mathrm{F}(\mathrm{P}<0,05)$.

\section{RESULTADO E DISCUSSÃO}

As análises do controle de qualidade da genotipagem dos caprinos Marota mostraram que 44.768 SNPs $(83,91 \%)$ dos 53.347 que compõem o Chip utilizado, foram polimórficos e não violaram os critérios de qualidade estabelecidos. As 86 amostras encontravam-se de acordo com os critérios estabelecidos e, por isso, foram todas incluídas nas análises genômicas de caracterização da diversidade genética nos dois rebanhos.

Como os marcadores SNPs, geralmente, são bialélicos (Caetano, 2009), considera-se elevado os valores obtidos para $\mathrm{H}_{\mathrm{o}}$ e $\mathrm{H}_{\mathrm{e}}$ nos animais do rebanho de conservação institucional, tanto nos adultos $\left(\mathrm{H}_{\mathrm{o}}=0,372 \pm 0,005\right.$ e $\left.\mathrm{H}_{\mathrm{e}}=0,405 \pm 0,007\right)$ como nas crias $\left(\mathrm{H}_{\mathrm{o}}=0,359 \pm 0,012\right.$ e $\mathrm{H}_{\mathrm{e}}=0,374 \pm 0,028$ ) (Tabela I). Esses valores podem ser indicativos de variabilidade genética no rebanho, reafirmando resultado obtido por Costa et al. (2008) com a utilização de marcadores microssatélites, o que pode ser visto como indício de que não está ocorrendo perda ou fixação significativa de alelos no rebanho. Porém, o fato do valor de $\mathrm{H}_{\mathrm{o}}$ nas crias ser um pouco menor que o observado nos adultos pode ser um indicativo de deriva genética, mostrando o risco de diminuição da heterozigosidade de uma geração para outra.

Valores do $\mathrm{F}_{\mathrm{IS}}$ observados nos animais adultos e nas crias, respectivamente, iguais a 0,086 $\pm 0,001 \mathrm{e}$ 0,042 $\pm 0,003$ (Tabela I), apesar de baixos, indicam que não convém considerar que a frequência de homozigotos na população está em equilíbrio em relação ao esperado para situação de acasalamento ao acaso. Porém, Barros et al. (2011) avaliaram a estrutura genética desse rebanho utilizando dados de genealogia e não constataram existência de consanguinidade $\left(\mathrm{F}_{\mathrm{IS}=}-0,22\right)$, 
resultado que consideraram em desacordo com a estreita base genética encontrada no rebanho analisado.

Segundo Lopes et al. (2013), correlações de baixa magnitude entre coeficiente de endogamia genômico e genealógico são esperadas. No entanto, quando o pedigree tem perfeito relacionamento entre indivíduos da população, o valor do parentesco pode variar devido à segregação e recombinação dos genes (Hill \& Weir, 2011). Como justificativa tem-se a ocorrência de recombinação gênica a partir de segmentos de homozigose, que não é considerado nas estimativas obtidas a partir da genealogia, além de falhas devido a erros no pedigree (Joaquim, 2016).

A indicação de que existe diversidade nesse rebanho, mas com incerteza quanto aos riscos de perda acentuada de variabilidade genética, significa que o núcleo institucional de conservação de caprinos Marota está atendendo à sua destinação, porém deve-se considerar o risco de ocorrência de consanguinidade. Assim, os resultados retratam de forma ampla o reflexo que o manejo com uso de reprodutores múltiplos (cinco animais por estação de monta) e com acasalamentos aleatórios, vem exercendo na composição genética do rebanho de conservação institucional.

A média da consanguinidade individual verificada no rebanho institucional foi $6,4 \%$ e, apesar de baixa, pode ser considerada como referência do risco de acasalamentos livres resultarem em perda ou fixação de genes no rebanho. Nesse sentido, Rodrigues et al. (2009), analisando a importância da estrutura populacional para definição de planos de conservação, constataram a tendência de incremento na consanguinidade associada a tamanho efetivo de população pequeno.

A constatação de consanguinidade no rebanho de conservação analisado se assemelha a resultados verificados em outras pesquisas, nas quais são apresentadas estratégias para ampliação de variabilidade genética em pequenas populações. Rodrigues et al. (2009) recomendam recorrer a manejo reprodutivo com controle de famílias. De forma similar, Adán et al. (2007), com base em resultados com ovinos da raça Ovella Galega, afirmaram que o controle de acasalamentos garante a manutenção do nível de consanguinidade. Em suínos Piau foi conseguido bom resultado com o controle reprodutivo baseado em uma metodologia de acasalamento entre animais com menor coancestralidade, mantendo as famílias fundadoras (Veronese et al.2014).
A utilização do Algoritmo Modelo de evolução diferencial, apresentado por Santos et al. (2016), também pode ser útil para rebanhos de conservação, pois explora a variabilidade genética e o desempenho, mas priorizando menor risco de consanguinidade e coancestralidade, definidos numa função objeto a ser maximizada por algoritmos diferenciais.

$\mathrm{O}$ rebanho particular apresenta valores de $\mathrm{H}_{\mathrm{o}}$ e $\mathrm{H}_{\mathrm{e}}$ $(0,374 \pm 0,024$ e $0,498 \pm 0,041$, respectivamente) similares aos observados nos animais adultos do rebanho institucional $(0,372 \pm 0,005$ e $0,405 \pm 0,007$, respectivamente) e o elevado valor do $F_{I S}(0,227 \pm 0,003)$ (Tabela I), indica a existência de consaguinidade. Assim, a introdução de progenitores do rebanho particular no rebanho institucional não é uma opção viável para ampliação de sua variabilidade genética. Além disso, o rebanho particular apresenta animais proveniêntes do rebanho institucional na sua composição, logo, existe relação de parentesco direta entre animais desses rebanhos.

Essa afirmação pode ser complementada ao se levar em consideração a dispersão dos animais dos dois rebanhos, apresentada em plano cartesiano formado pelos dois primeiros componentes principais, que explicaram juntos 8,9\% (o primeiro componente explicou $4,6 \%$ e o segundo explicou 4,3\%) da variação (Figura 1), pois segundo Patterson et al. (2006), a Análise de Componentes Principais permite detectar a estrutura de duas populações mesmo com nível pequeno de diferenciação.

Observa-se que a elipse $\mathrm{F}$, que representa os animais do rebanho particular, está dentro do círculo E, representando os animais do rebanho institucional, indicando semelhança genética entre os dois rebanhos, o que pode ser explicado pelo fato do rebanho particular utilizar os animais do rebanho institucional como opção para reposição. Também se observa maior dispersão entre os animais do rebanho institucional, que pode ser atribuída a maior quantidade de animais amostrados desse rebanho em relação ao rebanho particular (Figura 1).

A dispersão de 18 machos e 45 fêmeas, que corresponde a animais em idade reprodutiva do rebanho institucional analisados no ano de 2014, está apresentada na forma de dendograma (Figura 2). Os quadrados indicam a posição dos três machos reprodutores escolhidos de acordo com os critérios do Manejo I e os

\footnotetext{
Tabela I. Parâmetros populacionais estimados com dados obtidos por análises genéticas realizadas em animais de dois rebanhos Marota: um institucional (estratificado em adulto e cria) e outro particular, localizados no Piauí (Population parameters estimated based on genetic analysis of animals from two Marota herds: one institutional (stratified as adult and offspring) and one private herd in Piauí).
}

\begin{tabular}{|c|c|c|c|}
\hline \multirow{2}{*}{ Parâmetro populacional } & \multicolumn{2}{|c|}{ Rebanho Institucional } & \multirow{2}{*}{ Rebanho Particular } \\
\hline & Adultos & Crias & \\
\hline Número de animais analisados & 63 & 13 & 10 \\
\hline Heterozigosidade observada $\left(\mathrm{H}_{\mathrm{o}}\right)$ & $0,372 \pm 0,005$ & $0,359 \pm 0,012$ & $0,374 \pm 0,024$ \\
\hline Heterozigosidade esperada $\left(\mathrm{H}_{\mathrm{e}}\right)$ & $0,405 \pm 0,007$ & $0,374 \pm 0,028$ & $0,498 \pm 0,041$ \\
\hline$F_{1 S}$ & $0,086 \pm 0,001$ & $0,042 \pm 0,003$ & $0,227 \pm 0,003$ \\
\hline
\end{tabular}

$F_{\text {IS }}$ - Coeficiente de Consanguinidade Intrapopulacional 


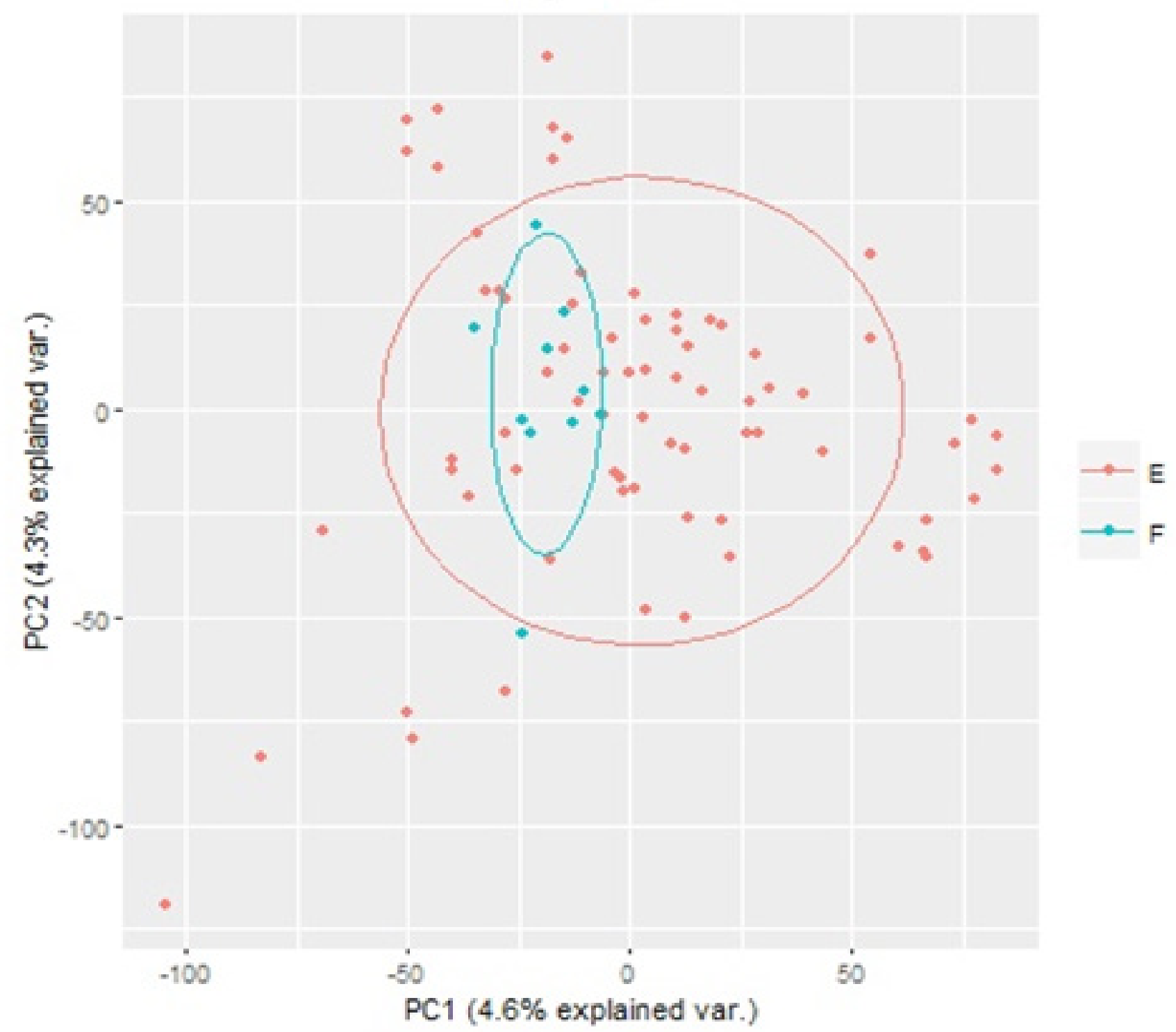

Figura 1. Dispersão dos animais em plano cartesiano formado pelo primeiro (PC1) e segundo (PC2) componentes principais. $\mathrm{O}$ círculo $\mathrm{E}$ representa os animais do rebanho de conservação institucional e a elipse $\mathrm{F}$ os animais do rebanho particular (Dispersion of animals in the cartesian plane formed by the first (PC1) and second (PC2) principal components. The circle $\mathrm{E}$ represents the animals of the institutional herd and the ellipse $\mathrm{F}$, animals of the private herd).

círculos, a posição dos três machos reprodutores escolhidos de acordo com os critérios do Manejo II.

No Manejo I a intensidade de seleção aplicada nos machos foi de 16,67\% (3 em 18). Com essa pressão de seleção foram escolhidos 3 animais que apresentaram coeficiente de consanguinidade igual a zero, dentre os 18 machos analisados do rebanho, cuja média desse coeficiente foi $4,4 \pm 4,0 \%$ (Tabela II).

A intensidade de seleção aplicada com base nos dados moleculares nas fêmeas foi de $66,67 \%$ (30 em 45). A média do coeficiente de consanguinidade das fêmeas selecionadas foi igual a $3,5 \pm 2,6 \%$, enquanto que, a média do coeficiente de consanguinidade de todas as fêmeas analisadas do rebanho foi $6,0 \pm 3,7 \%$, superior ao valor encontrado para os machos analisados (Tabela II).
É possível que a consanguinidade média mais elevada observada nas fêmeas do rebanho aumente o impacto delas na consanguinidade média da progênie. Com isso, ganha importância a escolha de fêmeas para reprodução, bem como o direcionamento dos acasalamentos, devendo ambos se basear em critérios que visem o aumento da variabilidade e a diminuição da consanguinidade. Segundo Marques et al. (2015), a presença de meias irmãs num rebanho formado com prevalência de fêmeas, justifica a consanguinidade positiva dentro do rebanho e implica no aumento dos riscos de endogamia também via matriz.

$\mathrm{Na}$ escolha de machos e fêmeas realizada por sorteio para uma estação de monta no Manejo II, a média do coeficiente de consanguinidade dos machos foi igual a $7,94 \pm 6,0 \%$ e das fêmeas igual a $5,6 \pm 3,9 \%$. Nes- 


$\begin{array}{ccccccc}0.12 & 0.1 & 0.08 & 0.06 & 0.04 & 0.02 & 0 \\ 1 & \perp & \perp & \perp & \perp & \perp & \downarrow\end{array}$

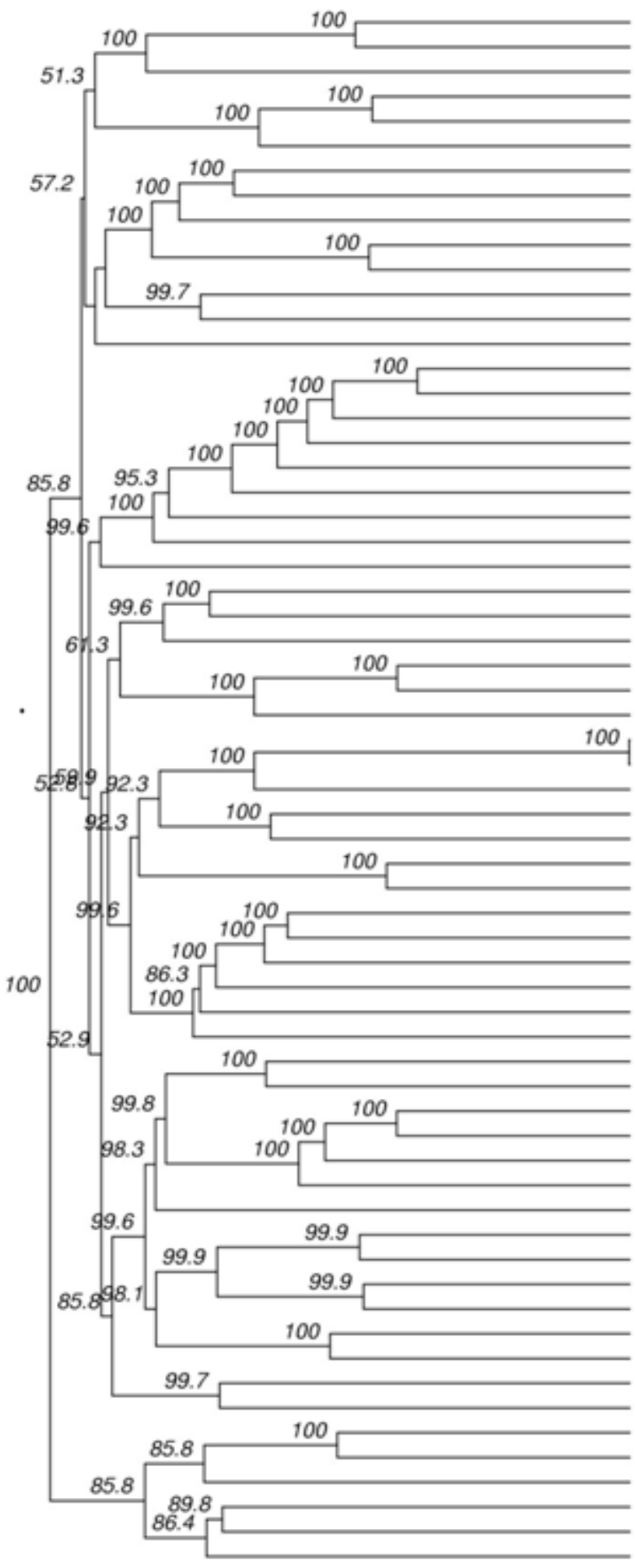

se manejo, a média do coeficiente de endogamia nas fêmeas foi $60,0 \%$ superior ao percentual obtido para as fêmeas escolhidas de acordo com o Manejo I.

Ao se considerar a simulação de 10 pares de acasalamentos de cada reprodutor, constatou-se que a média do coeficiente de consanguinidade dos casais obtidos de acordo com o Manejo I $(3,5 \pm 2,6 \%)$, foi estatisticamente inferior à média dos pares acasalantes formados de acordo com o Manejo II $(5,7 \pm 4,0 \%)$ (Tabela II), pelo teste $\mathrm{F}(\mathrm{P}<0,05)$.

Esses resultados mostram ser pequena a contribuição da escolha aleatória de animais de reprodução para controlar a endogamia em rebanhos com situação semelhante ao rebanho institucional. Consequentemente, pode-se considerar como uma demonstração da funcionalidade dos painéis de marcadores nos estudos de conservação genética, bem como, da importância do uso dessa tecnologia molecular para auxiliar o manejo genético em rebanhos de conservação.

Além disso, teoricamente poderia ampliar a variabilidade genética se os reprodutores selecionados com base em critérios de divergência genética forem acasalados apenas com fêmeas de ramos mais distantes deles no dendograma, ou seja, usar acasalamento associativo negativo, pois pode aumentar a quantidade de animais heterozigotos, resultando em maior variabilidade genética.

Essa estratégia de manejo reprodutivo é usada por criadores que procuram complementação funcional acasalando animais com características diferentes, consequentemente, aumenta a quantidade de animais com maior heterozigose, implicando em maior variabilidade genética, que é importante em rebanhos de conservação.

Considera-se também que a dispersão dos animais no dendograma obtido com dados moleculares, pode ser utilizada para orientar a seleção de animais para reposição e para descarte em rebanhos de conservação nos quais a opção principal seja recorrer à reposição com animais do próprio rebanho, prática que leva ao aumento da consanguinidade da progênie, como foi veri- 
Tabela II. Média e desvio padrão do coeficiente de consanguinidade de machos e fêmeas selecionados de acordo com os Manejos I e II, e também da simulação de acasalamentos de uma estação de monta em rebanho de conservação in situ (Mean and standard deviation of the coefficient of inbreeding of males and females selected based on Management I and II, and the simulation of matings of one breeding season in the conservation heard in situ).

\begin{tabular}{|c|c|c|c|}
\hline \multirow{2}{*}{ Escolha de machos e fêmeas para estação de monta } & \multicolumn{3}{|c|}{ Média e desvio padrão do $F_{\mathrm{IS}}(\%)$} \\
\hline & 3 machos & 30 fêmeas & ${ }^{* * *}$ Acasalamentos simulados \\
\hline *Manejo I & 0,0 & $3,5 \pm 2,6$ & $3,5 \pm 2,6^{b}$ \\
\hline${ }^{* *}$ Manejo II & $7,94 \pm 6,0$ & $5,6 \pm 3,9$ & $5,7 \pm 4,0^{\text {a }}$ \\
\hline Média e desvio padrãodo $F_{\text {IS }}(\%)$ no rebanho & $4,4 \pm 4,0$ & $6,0 \pm 3,7$ & \\
\hline
\end{tabular}

* Manejo I - Escolha de machos e fêmeas mais distantes no dendograma do rebanho (Figura 2), dentre os animais de menor coeficiente de consangüinidade e definição de acasalamentos de acordo com os mesmos critérios;

** Manejo II - Escolha aleatória de machos e fêmeas para acasalamentos ao acaso na Estação de monta;

*** Medias do coeficiente de consanguinidade dos acasalamentos simulados de acordo com os manejos I e II, com letra diferente na coluna diferem pelo teste $\mathrm{F}(P<0,05)$.

ficado nesse estudo (Tabela II). Nesse caso, convém descartar animais geneticamente semelhantes que se apresentam no mesmo ramo do dendrograma, com elevado coeficiente de consanguinidade individual.

Diante da previsibilidade de redução de custo da genotipagem pela automação tecnológica (Pereira et al., 2013) e da possibilidade de confecção de Chips de menor densidade e portanto mais baratos, considera-se que a sua utilização no manejo em rebanhos de conservação in situ, fechados e com pequeno efetivo de população, pode se tornar uma forma simples e prática de manter variabilidade genética em rebanhos dessa natureza, mesmo com a utilização de múltiplos reprodutores.

\section{CONCLUSÃO}

Existe variabilidade genética nos rebanhos analisados, porém com indício de consanguinidade;

Em rebanho com pequeno tamanho efetivo e onde a reposição é feita com animais do próprio rebanho, a definição de acasalamentos com base em critérios genéticos acurados é opção para controle de consanguinidade.

\section{AGRADECIMENTOS}

A Embrapa Meio Norte e ao senhor José Ferreira Dantas Filho, por autorizarem a análise dos rebanhos de conservação de caprinos Marota;

Ao Instituto Federal do Piauí pela colaboração financeira com recursos do Programa de Apoio à Pesquisa Científica e Tecnológica (ProAGRUPAR).

\section{BIBLIOGRAFIA}

Adán, S; Fernández, M; Justo, JR; Rivero, CJ; Rois, D \& Lama, J 2007, 'Análisis de la información genealógica em la raza ovina Ovella galega', Archivos de Zootecnia, vol. 56, n 1, pp. 587-592.

Araújo, AM; Beffa, LM; Almeida, MJO; Abreu, UP; Cavalcante, DH; Leal, TM \& Paiva, SR 2009, 'Crescimento e mortalidade em um rebanho de Conservação de Caprinos Marota no Brasil', Revista Científica de Produção Animal, vol. 11, n², pp. 103-109.
Barros, EA; Ribeiro, MN; Almeida, MJO \& Araújo, AM 2011 , 'Estrutura populacional variabilidade genética da raça caprina Marota', Archivos de Zootecnia, vol. 60, n² 2, pp. 543-552.

Caetano, AR 2009, 'Marcadores SNP: conceitos básicos, aplicações no manejo e no melhoramento animal e perspectiva para o futuro', Revista Brasileira de Zootecnia, vol. 38, n 8, pp.64-71.

Costa, MDS; Araújo, AM; Moraes, JDB; Cunha, RMS; Campelo, JEG; Lima, SEF; Oliveira, JA; Almeida, GM.; Silva, FR. \& Almeida, MDO 2008, 'Caracterização genética de caprinos Marota no Estado do Piauí por meio de microssatélites de DNA', VII Simpósio Brasileiro de Melhoramento Animal, São Carlos, pp. 1-4.

Curi, RA; Meira, CT; Beltrán, NAR; Silva, JAIV \& Mota, MDS 2013, 'Seleção assistida por marcadores para o melhoramento do desempenho de equinos em corridas', Boletim de Indústria Animal, vol. 70, n 1, pp. 88-102.

Egito, AA; Mariante AS \& Albuquerque, MSM 2002, 'Programa brasileiro de conservação de recursos genéticos animais', Archivo de Zootecnia, vol. 51, n 193-194, pp. 39-52.

Goudet, J 2005, 'Hierfstat, a package for R to compute and testhierarchical F『statistics', Molecular Ecology Resources, vol. 5, n 1, pp. 184-186.

Hill WG \& Weir BS 2011, 'Variation in actual relationship as a consequence of Mendelian sampling and linkage', Genetics Research, vol. 93, $\mathrm{n}^{\circ} 1$, pp. 47-64.

Illumina. Illumina Infinium HTS Assay. 2013, Manual Protocol, acessado em 26 de junho de 2016, <http://support.illumina.com/content/ dam/illumina-support/documents/documentation/chemistry_documentation/humanomniexpress-24/infinium_hts_assay_manual_protocol_experienced_user_card_15045737_a.pdfs.

Joaquim, LB 2016, 'Estrutura genômica de uma população de suínos base Landrace', Dissertação de Mestrado, Universidade Estadual Paulista, Brasil.

Jombart, T \& Ahmed, I 2011, 'Adegenet 1.3-1: new tools for the analysis of genome-wide SNP data', Bioinformatics, vol. 27, $n^{\circ} 21$, pp. 3070-3071.

Kamvar, ZN; Tabima, JF \& Grünwald, NJ 2014, 'Poppr: an R package for genetic analysis of populations with clonal, partially clonal, and/ or sexual reproduction', PeerJ, v. 2, p. e281.

Lopes, MS; Silva, FF; Harlizius, B; Duijvesteijn, N; Lopes, PS; Guimarães, SEF; Knol, EF 2013, Improved estimation of inbreeding and kinship in pigs sing optimized SNP panels, BMC Genetics, vol. 14, n 1, p. 92.

Mariante, AS; Albuquerque, MSM \& Ramos, AF 2011, 'Criopreservação de recursos genéticos animais brasileiros', Revista Brasileira Reprodução Animal, vol. 3, n 2, pp. 64-68.

Marques, ITO; Sarmento, JLR; Biagiotti, D; Vale, KAG; Carvalho, KSS \& Britto, FB 2015, 'Caracterização da diversidade genética de ovinos Santa Inês em fazendas do Estado do Piauí, Revista Brasileira de Saúde e Reprodução Animal, vol. 16, n 3, pp. 523-534. 
Patterson, N; Price, A \& Reich, D 2006, 'Population Structure and Eigen analysis', PLoS genetics, vol. 2, n' 12, p. el90.

Pereira, GL; Rosa, KO; Curi, RA; Regitano, LCA \& Mota, MDS 2013, 'Estado da arte do sequenciamento genômico na pecuária', ARS Veterinária, vol. 29, n³, pp. 190-199.

Purcell, S; Neale, B; Todd-Brown, K; Thomas, L; Ferreira, MAR; Bender, D; Maller, J; Sklar, P; Bakker, PIW; Daly, MJ \& Sham, PC 2007, PLINK: a tool set for whole-genome association and population-based linkage analyses. The American Journal of Human Genetics, vol. 81, $\mathrm{n}^{\circ}$ 3, pp. 559-575.

Resende, MDV; Lopes, PS; Silva, RL \& Pires, IE 2008, 'Seleção Genômica Ampla (GWS) e maximização da eficiência do melhoramento genético', Pesquisa Florestal Brasileira, ${ }^{\circ}$ 56, pp. 63-77.

Rodrigues, DS; Ribeiro, MN; Oliveira, SMP; Lima, FAM; Villarroel, ABS; Pacheco, ACL \& Santos, LH 2009, 'Estrutura populacional de um rebanho da raça Morada Nova como contribuição para a conservação', Ciência Animal, vol. 19, n 1, pp. 103-110.
Santos, NPS; Sarmento, JLR; Carvalheiro, R; Campelo, JEG; Sousa, WH; Filho, LASF; Neto, AAR \& Biagiotti, D 2016, 'Contribuição genética ótima aplicada à seleção de ovinos Santa Inês', Pesquisa Agropecuária Brasileira, vol. 51, n 6, pp. 745-750.

Silva Filho, E 2012. Caracterização da variabilidade genética por marcadores microssatélites nos bovinos da raça Pé Duro em rebanho de conservação e de bovinos da raça Tabapuã em rebanho sob seleção. Tese (Doutorado em Ciência Animal). Universidade Federal do Piauí, Brasil.

Sokal, RR \& Michener, CD 1958, 'A statistical method for evaluating systematic relationships', University of Kansas Science Bulletin, vol. 38, n²2, pp. 1409-1438.

Veroneze, R; Lopes, PS; Guimarães, SEF; Guimarães, JD; Costa, EV; Faria, VR \& Costa, KA 2014, 'Using pedigree analysis to monitor the local Piau pig breed conservation program', Archivos de Zootecnia, vol. 63, n² 241 , pp. 45-54. 